\title{
IdeAs
}

Idées d'Amériques

\section{Formas de la dominación social en las ficciones alegóricas y metafóricas realizadas en épocas de la dictadura y la postdictadura en Argentina}

Forms of social domination in the allegorical and metaphorical fictions made in times of dictatorship and post-dictatorship in Argentina

Formes de domination sociale dans les fictions allégoriques et métaphoriques durant la dictature et la post-dictature en Argentine

\section{Ana Laura Lusnich}

\section{OpenEdition}

\section{Journals}

Electronic version

URL: https://journals.openedition.org/ideas/1528

DOI: $10.4000 /$ ideas. 1528

ISSN: 1950-5701

\section{Publisher}

Institut des Amériques

\section{Electronic reference}

Ana Laura Lusnich, "Formas de la dominación social en las ficciones alegóricas y metafóricas realizadas en épocas de la dictadura y la postdictadura en Argentina", IdeAs [Online], 7 | 2016, Online since 30 June 2016, connection on 18 October 2022. URL: http://journals.openedition.org/ideas/1528 ; DOI: https://doi.org/10.4000/ideas. 1528

This text was automatically generated on 18 October 2022

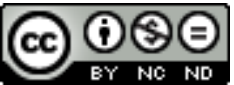

Creative Commons - Attribution-NonCommercial-NoDerivatives 4.0 International - CC BY-NC-ND 4.0 https://creativecommons.org/licenses/by-nc-nd/4.0/ 


\section{Formas de la dominación social en las ficciones alegóricas y metafóricas realizadas en épocas de la dictadura y la postdictadura en Argentina}

Forms of social domination in the allegorical and metaphorical fictions made in times of dictatorship and post-dictatorship in Argentina Formes de domination sociale dans les fictions allégoriques et métaphoriques durant la dictature et la post-dictature en Argentine

Ana Laura Lusnich

\section{Introducción. Los años de la dictadura y la transición a la democracia}

1 El 24 de marzo de 1976 María Estela Martínez de Perón, presidenta a cargo del gobierno argentino desde 1974 luego de la muerte de su esposo, Juan Domingo Perón, fue depuesta por un golpe de estado que dio origen a una feroz dictadura. La Junta de Comandantes integrada por el teniente general Jorge Rafael Videla, el almirante Eduardo Emilio Massera y el brigadier general Orlando Agosti asumió el poder, designando como presidente de facto a Jorge Rafael Videla. En el curso de estos años los planes económicos priorizaron la especulación financiera y las deudas pública y privada se incrementaron de forma considerable. La Junta Militar impuso el terrorismo de estado que, más allá de perseguir el accionar de las facciones guerrilleras que surgieron en los años 70, se dedicó a destruir cualquier tipo de participación popular. El régimen militar ejerció la censura y la represión sobre las fuerzas democráticas de la sociedad, con especial atención en las organizaciones sindicales, los obreros, los estudiantes y los 
intelectuales, eliminando mediante el miedo y el terror las voces disidentes a las políticas dictatoriales (Masiello F., 2014). Con las elecciones nacionales realizadas el 30 de octubre de 1983 y la asunción a la presidencia de Raúl Alfonsín el 10 de diciembre de ese año, la Argentina iniciaría un lento y complejo proceso de recuperación de la democracia. En una primera fase, coincidente con la presidencia de Alfonsín en el poder $^{1}$, se lograría revertir el silencio y la inhibición social a través de un dinámico debate intelectual y la apropiación del espacio público por parte de diferentes sectores de la sociedad. Sin embargo, la transición democrática estuvo sometida a múltiples tensiones y contramarchas generadas por el poder militar que aún contaba con un aparato en actividad que se oponía a la política de los derechos humanos del alfonsinismo ${ }^{2}$. Asimismo, las consecuencias y los traumas heredados de la etapa dictatorial (el exilio político, las desapariciones de personas, la desarticulación de las instituciones republicanas) perduraron por años interfiriendo en el desarrollo armónico de la vida política del país (Avellaneda A., 2014).

2 En su relación con los programas políticos y culturales de estas etapas de dictadura y transición a la democracia, el campo cinematográfico ofreció diferentes respuestas, convirtiéndose en un segmento activo, siempre atento a los hechos históricos. De acuerdo con las prácticas cinematográficas impuestas por la dictadura, que incluyeron la censura, la persecución e incluso la muerte de quienes se oponían abiertamente al régimen ${ }^{3}$, tanto como el otorgamiento de créditos y beneficios comerciales a quienes lo apoyaban, el panorama cinematográfico comprendido entre 1976 y 1983 incluyó dos tendencias cinematográficas disidentes (los documentales realizados en el exilio político y las ficciones hermético-metafóricas desarrolladas en el país) y una tercera que reunía a una serie variada de géneros que, en sus contenidos y perspectivas ideológicas, coincidían en avalar la idiosincrasia del gobierno militar destacando los valores de la familia tradicional, la pérdida de la cultura del trabajo y la naturalización de la violencia. Los documentales realizados en el exilio por grupos o realizadores independientes que se vieron forzados a dejar el país, se convirtieron en un baluarte de la denuncia de la violación de los derechos humanos, difundiendo en el exterior y con el apoyo de organismos internacionales los hechos de represión y tortura. De este conjunto surgieron los primeros audiovisuales que dejaron testimonio de la lucha emprendida por los familiares de las personas desaparecidas, en tanto otros se dedicaron a reflexionar en profundidad sobre el exilio y la condición de los exiliados políticos ${ }^{4}$. Ejercitando la resistencia al poder político en el escenario mismo de los hechos, por su parte, las ficciones hermético-metafóricas confrontaron el cine comercial producido a instancias de la ideología dominante, incitando la crítica transversal a las situaciones que se vivían en la Argentina mediante la construcción de relatos que evadían la estética realista-mimética. Frente a estas tendencias, el Estado privilegió financiar comedias familiares, comedias picarescas y films de aventura y/o acción, que en gran medida se organizaban narrativamente en torno a las actividades violentas emprendidas por comandos policiales, militares y paramilitares. Mediante estos films se contribuía a la promoción social de las Fuerzas Armadas (como ejemplos, Dos locos en el aire, Palito Ortega, 1976, se concentraba en la Fuerza Aérea; Brigada en acción, Palito Ortega, 1977, en tanto, destacaba el desempeño policial), e incluso se aceptaba el accionar de grupos de poder que hacían uso de las armas sin formar parte del Estado. Así funcionó una popular serie de películas interpretadas por tres agentes que se desempeñaban persiguiendo, secuestrando y asesinando personas, y que luego de unos meses de ocurrido el golpe de estado de 1976 daba a conocer su tercera 
producción titulada La aventura explosiva, con dirección de Ricardo Bauleo y Orestes Trucco.

3 Comparativamente, los primeros años de la postdictadura se caracterizaron por el incremento industrial por parte del Instituto Nacional de Cine, la abolición de la censura ejercida hasta ese entonces por el Ente de Calificación Cinematográfica y el crecimiento de los espectadores que consumían cine nacional. En lo concerniente a las modalidades textuales, los films de la transición compartieron el afán crítico y reflexivo, colaborando con la revisión del pasado reciente. Una de las vertientes cinematográficas que tuvo amplio desarrollo y aceptación fue la de las ficciones reparadoras (Noriega G., 2009), cuyo ejemplo paradigmático es La historia oficial (Luis Puenzo, 1985). Estas ficciones se caracterizaban por un marcado estilo realista que recuperaba los sucesos ocurridos en la dictadura, pretendiendo con estas referencias directas a los hechos recomponer el tejido social y contribuir al fortalecimiento del sistema democrático de gobierno (Visconti M., 2014). Significativo valor tuvieron asimismo los documentales de montaje realizados en la época del alfonsinismo ( $\mathrm{L} a$ República Perdida I y II, Miguel Pérez, 1983 y 1986, entre otros), destinados a recoger testimonios audiovisuales del pasado histórico nacional y, fundamentalmente, a enarbolar lo valores republicanos por sobre los sistemas de gobierno no representativos y dictatoriales (Aguilar G., 2012). Complementariamente, en este período inaugural de recuperación de la democracia las ficciones hermético-metafóricas originadas en los años tempranos de la dictadura continuaron vigentes y con una marcada productividad, proveyendo una perspectiva compleja de la realidad nacional que superaba las marcadas dicotomías y los estereotipos formulados por los films de las otras tendencias dominantes ${ }^{5}$.

\section{Las ficciones hermético-metafóricas. Singularidades textuales}

4 De acuerdo con el panorama histórico y cinematográfico descripto, es posible sostener que las ficciones hermético-metafóricas que constituyen el objeto de estudio de este trabajo constituyeron una tendencia cinematográfica alternativa que supo plasmar críticamente los conflictos principales de su tiempo histórico. En lo que respecta a los parámetros textuales que singularizan a esta tendencia, en una serie de artículos anteriores identificamos las orientaciones generales y las modalidades centrales que adoptaron el sistema narrativo y la puesta en escena ${ }^{6}$. En su carácter coyuntural e histórico dedujimos que la corriente participó de un doble movimiento que abarcaba la asimilación de los parámetros estéticos e ideológicos de la modernidad cinematográfica en el medio local y, con igual importancia, el ejercicio de la reflexión y el comentario transversal del contexto político y social del cual proceden (Lusnich A.L., 2011)7. Comprendimos que el rasgo principal que caracteriza a estas ficciones es la adhesión de los films a una función diferenciada y compensatoria, en la cual los acontecimientos representados y sus referentes se asocian mediante los recursos de la metáfora y la alegoría, alentando lecturas del presente histórico y de las principales marcas de época: el autoritarismo, el terror, la falta de expresión, el encierro. Advertimos que cada una de estas funciones predomina en diferentes niveles estructurales de los relatos. Entendidas como representaciones de ideas o conceptos generales $u$ abstractos que reaparecen en los sujetos dramáticos o en objetos y/o componentes cercanos a estos 
(Fletcher A., 2002), las alegorías se localizan en la plano narrativo y en la configuración del sistema de personajes de los films estableciendo estructuras binarias de relaciones que se circunscriben a los términos oprimidos/opresores y víctimas/victimarios. Por su parte, la producción de metáforas se evidencia en el diseño de la puesta en escena y en la manipulación de las coordenadas espacio-temporales, funcionando en los films su definición estética tradicional -para la cual las metáforas establecen una relación de semejanza o cualidad común entre dos términos-, así como otras contemporáneas que sostienen que este tipo de operaciones se convierten en un mecanismo de emergencia y producción de contenidos y conocimientos que no se hacen presentes de forma directa por otros medios (Angenot M., 1982; Maillard C., 1992). En tercer lugar, desciframos que el uso del lenguaje cinematográfico en general, y de algunos recursos en particular, contribuyen al hermetismo o a la falta de claridad de las historias, personajes o puesta en escena, siendo este el caso de los contrastes luminosos, la ausencia de una luminosidad prístina y los encuadres extremadamente cerrados sobre los personajes, en aquellos films que tematizan el encierro o la opresión; o el uso de picado y contrapicado, en aquellos que materializan las jerarquías de poder y la confrontación entre víctimas y victimarios.

5 Respecto de las variantes principales que se fueron generando en el interior de la tendencia en los años de la dictadura y la postdictadura, ha sido posible constatar dos orientaciones generales, que se definen a partir del encapsulamiento o bien del despliegue de los sistemas narrativo y de puesta en escena (Lusnich A.L, 2014). La primera, que incluye los film La isla (Alejandro Doria, 1979), La nona (Héctor Olivera, 1979), Los pasajeros del jardín (Alejandro Doria, 1982), Los enemigos (Eduardo Calcagno, 1983) y Hay unos tipos abajo (Rafael Filipelli y Emilio Alfaro, 1985), representa situaciones de encierro y terror enmarcadas en casas de familia o en instituciones de salud que funcionan metafóricamente aludiendo a esos "otros" espacios -comisarías, cárceles, centros clandestinos de detención- en los cuales la tortura y el asesinato de personas se concretaba de manera efectiva. El caso de La isla es sintomático al respecto, debido a que las prácticas de la dominación de los ciudadanos aparecen localizadas en una clínica de salud mental, suministrando los médicos y enfermeros píldoras y otros tratamientos con el objetivo de la domesticación y la neutralización física y mental de los pacientes. La segunda modalidad reúne un conjunto de films -Los miedos (Alejandro Doria 1980), El poder de las tinieblas (Mario Sábato, 1979), Crecer de golpe (Sergio Renán, 1976), El hombre del subsuelo (Nicolás Sarquís, 1981), El agujero en la pared (David José Kohon, 1982), entre los más representativos- que operan mediante la expansión espacio-temporal y narrativa. Se elaboran así derroteros dramáticos complejos, en los que la huída y la necesidad de cambiar periódicamente de lugar determinan la posibilidad de sobrevivir. Estos films multiplican las posibilidades espaciales y temporales, incorporándose a la puesta en escena categorías topográficas novedosas (espacios superficiales y otros que se corresponden con las profundidades, como sucede en El poder de las tinieblas a través de escenas que transcurren en las calles y otras en los túneles por los que circulan los metros), o la alternancia de situaciones dramáticas que corresponden a momentos biográficos diferentes ( $\mathrm{El}$ agujero en la pared combina el pasado y el presente del personaje, un fotógrafo que ha firmado un pacto con el diablo a cambio de dinero y de fama, diseñándose una suerte de rompecabezas que no adquiere una lógica narrativa coherente). En su efecto de corpus, comprobamos que estas dos versiones adquieren una función complementaria dado que en ellas se manifiestan el extenso mosaico de situaciones dramáticas que afloran de forma intempestiva en los 
años del gobierno militar (Lusnich A.L., 2014). Si se tienen en cuenta los desarrollos dramáticos y las resoluciones de las historias, se aprecia que la redención de los personajes o el hallazgo de una salida no aparecen como una posibilidad viable y concreta. De esta manera, junto con las disposiciones alegóricas y metafóricas mencionadas que transportan las situaciones dramáticas al presente histórico de la dictadura, cobra fuerza la presentación de los sujetos dramáticos a través de sus experiencias y vivencias personales. Determinados por las circunstancias individuales y/o colectivas en las cuales aparecen inmersos -aquellos que ofician como víctimas e incluso algunos de los que representan a los victimarios-, los sujetos dramáticos esbozan identidades fracturadas e inestables que los llevan al aislamiento del entorno familiar y social, al exilio o a la locura.

6 A partir de lo señalado, con la intención de conocer el grado de conocimiento y reacción de esta corriente cinematográfica respecto de las prácticas políticas y las situaciones de terror impuestas en los años de gobierno de facto, a continuación nos dedicaremos a desarrollar dos aspectos particulares. Uno de ellos procura analizar la representación de la dominación ejercida por el poder militar sobre los individuos y el conjunto social, con énfasis en los emplazamientos y/o los desplazamientos forzados o voluntarios de los sujetos dramáticos. El segundo comprende la identificación, en estas situaciones históricas asociadas al control y a la persecución social por parte del Estado, de subjetividades que se caracterizan por la fractura, la inestabilidad y la angustiosa necesidad de preservar la vida. Para desarrollar estos aspectos el análisis se centrará en dos films de la tendencia: Los miedos, Alejandro Doria, 1980, y Hay unos tipos abajo, Rafael Filipelli y Emilio Alfaro, $1985^{\circ}$. Representativos de los dos tramos históricos en los que la tendencia analizada tuvo un una producción sostenida (Los miedos fue realizado en un momento en el que la dictadura recrudecía su poder coercitivo; Hay unos tipos abajo forma parte de los primeros años de la transición a la democracia), los films se destacan por otras dos situaciones en particular. Por un lado, exhiben las características de las dos orientaciones narrativas y de puesta en escena previamente mencionadas asociando la constricción de estos aspectos del texto fílmico a la forma del exilio interior (Hay unos tipos abajo) y su expansión a la del exilio exterior que lleva a los personajes a peregrinar hacia otro sitio que no es familiar (Los miedos). Por otra parte, los films articulan las categorías victimario/víctima y opresores/oprimidos de forma creativa y plural esbozando múltiples matices. Estos incluyen algunas formulaciones radicales (como sucede en Los miedos), que derivan en la confrontación física extrema e irreversible entre los propios sujetos oprimidos.

\section{Los miedos. La experiencia de la diáspora, confrontación y supervivencia}

7 Los miedos, film de Alejandro Doria estrenado comercialmente en Argentina el 14 de agosto de 1980, se organiza narrativamente en base al periplo de un grupo de personas que se ven obligadas a peregrinar de la ciudad de Buenos Aires -asolada por una peste desconocida- hacia el sur del país, espacio que promete la preservación de la vida9 ${ }^{9}$. En este escape colectivo el film tematiza y construye audiovisualmente la situación de la migración forzada de personas, resultado de la persecución política de la época, representando en la mudanza del espacio que se habita hacia otro distante y neutral la expatriación de un amplio número de argentinos a diferentes puntos del planeta. En el 
film el diagrama narrativo y el diseño de la puesta en escena exhiben marcados contrastes entre los lugares de procedencia y de destino. Las primeras secuencias se localizan en una ciudad azotada por la peste, que contiene edificios abandonados y en ruinas, y que es transitada por enfermeros/militares que se valen de altoparlantes, sirenas y disparos para controlar y perseguir a los ciudadanos. Su misión es sanear completamente el área, eliminar a quienes estén infectados o se transformen en una amenaza social. El sur argentino, los sucesivos parajes naturales que van integrando el periplo narrativo del grupo (un bosque petrificado, las salinas y la Playa Unión de la localidad de Puerto Madryn, situados en la provincia de Chubut) constituyen por su parte un escenario despojado e igualmente poco acogedor. Sus notas ambientales (espacios abiertos en los que no prospera la vegetación y predomina el viento) condicen con las circunstancias que generalmente caracterizan a los exiliados políticos. En su expresión individual y colectiva, los personajes asumen en estos espacios la condición de "sujetos nómades" que han perdido toda relación con lo que era permanente y estable, percibiendo lo nuevo como extraño y ajeno (Fernández Bravo Á. y Garramuño F., 2003). De acuerdo con las operaciones metafóricas efectuadas en el plano narrativo y en la puesta en escena, la situación del exilio forzado al exterior del país se recompone mediante el tránsito de los personajes a un entorno geográfico desconocido, alejado y distante, al que se llega superando numerosos límites y pasos fronterizos. En el film los sujetos dramáticos van desde el centro de la ciudad hacia sus alrededores, para luego encarar el viaje al sur. En esa segunda fase, atraviesan ríos, bordean bosques, atraviesan salinas y sortean diferentes escollos naturales. Por su parte, la provocación de la diáspora generalizada, que reúne a un conjunto de personas en iguales circunstancias, se atribuye a un poder local o nacional que decide hostigar y aniquilar a una porción de los habitantes. Las prácticas de control y dominación incluyen, como mencionamos, diatribas e injurias orales, difundidas con los altavoces, así como las acciones violentas que aíslan y eliminan a las personas sospechadas. Frente a este estado de cosas, la movilización y la huída se concibe como única salida posible.

8 Heterogéneo en su constitución, el grupo de personas que escapan al sur de la Argentina se encuentra integrado por siete personajes que representan géneros, generaciones e idiosincrasias diferentes: la vieja, la embarazada, la monja, la prostituta, el asesino, el deficiente mental y el futbolista. Presentándose como un muestrario de la sociedad argentina de la época -metonímicamente el asesino hace visibles las particularidades que en los años de la dictadura adoptaron los grupos de tareas ${ }^{10}$; luego del mundial de fútbol jugado en el país en 1978 el futbolista se encontraba en el centro de la escena nacional; las mujeres representan diferentes facetas de la femineidad-, el conjunto se desmadra de forma progresiva, siendo el personaje de la futura madre -y su hijo- los únicos sobrevivientes. En su travesía hacia el sur, el relato se concentra en las respuestas de los personajes frente al horror -la exigencia de abandonarlo todo con el propósito de sobrevivir-, siendo dos los aspectos sobre los cuales se focaliza y se reflexiona agudamente: la condición del exiliado y la exacerbación de un estado de terror que no cesa con el viaje. Respecto del primero de los temas los personajes que componen la caravana exhiben las dos notas que habitualmente caracterizan el estado del expatriado político: la experiencia solitaria y la ausencia de una identidad estable. Como explican los historiadores y teóricos que han investigado los fenómenos de los exilios y las diásporas, los sujetos nómades adoptan habitualmente una subjetividad fracturada y múltiple, que desencadena un proceso de hibridación y contingencia a través del cual se vivencia el desdoblamiento del yo y la ausencia de la armonización de 
los contrarios: el territorio de origen y, luego, el de llegada (García Canclini N., 2000). Edward Said comprende asimismo que esta condición discontinua del exilio provoca la desconexión con el grupo de pertenencia, el espacio común y la memoria colectiva. Se trata de una experiencia en líneas generales solitaria, que dependiendo de cada caso, puede distanciar a quien lo atraviesa de todas las relaciones y compromisos, y que aún puede desembocar en la pérdida de la perspectiva crítica y el coraje moral (Said E., 2005). En el film analizado, si bien los siete miembros del equipo componen en un principio un colectivo que se nuclea en torno a un mismo objetivo, el terror que los destaca y la inexistencia de lazos afectivos reales originan feroces enfrentamientos verbales y físicos que conducen al exterminio de la mayoría de ellos. Destacando el individualismo de los personajes por sobre el hallazgo de soluciones consensuadas y colectivas, cada personaje obra de acuerdo con su propia voluntad, aflorando las pasiones y los sentimientos personales que derivan en encuentros intensos, peleas y asesinatos. Al momento de llegada a la tierra de destino, representada por la costa patagónica en algún punto de su extensión, la madre y el discapacitado mental -los dos únicos integrantes que se mantienen con vida- tienen un último acercamiento. Luego de un balbuceo incomprensible, el deficiente mental ingresa sin retornar al Mar Argentino esbozando metafóricamente la actitud del sujeto que se sacrifica en honor del niño -la nueva vida, el futuro- que está por nacer.

9 La exacerbación del estado de terror, por su parte, se pone de manifiesto en el desempeño de los sujetos dramáticos y en el estilo interpretativo que los caracteriza. El film, al igual que la mayoría que compone la tendencia de las ficciones herméticometafóricas, opera mediante el desplazamiento del canon realista históricamente dominante en el cine de comercial argentino tendiendo en cambio a la opacidad, el teatralismo y la afectación dramática. Como se señaló en la introducción del artículo, los films de esta tendencia recuperan los postulados del cine moderno que en los años 60 y 70 desafiaron la representación realista-mimética del mundo con la incorporación de la subjetividad, la multiplicación de los puntos de vista, el estilo indirecto libre y la gestualidad no imitativa, entre otras novedades ${ }^{11}$. Ahora bien, además de expresar un acto de rebeldía frente a los designios culturales hegemónicos que se mantenían intactos en las comedias y películas de aventuras y de acción filmadas durante el proceso, y aún en las ficciones reparadoras de la postdictadura, la asunción de una interpretación teatralista no mimética ofrecía otro campo de posibilidades expresivas. En su análisis del teatro argentino, refiriéndose a la etapa de la dictadura, Osvaldo Pellettieri sostuvo que lo mimético no alcanzaba entonces para mostrar la monstruosidad de lo que ocurría, y que el teatralismo "tiene la posibilidad de ser más fuertemente simbólico que el realismo, y de mostrar más con menos elementos" (Pellettieri O., 2008: 81). En esta dirección, los personajes de Los miedos adoptan una gestualidad no imitativa que elude la cotidianeidad y la espontaneidad a favor de una construcción diferenciada y original en la que los cuerpos asumen un protagonismo absoluto por sobre las palabras. Respecto del empleo de la palabra, cabe aclarar que no solo se la desvaloriza como mecanismo de diálogo y reflexión, sino que a su vez se la sustituye por sonidos guturales que acercan a los seres humanos a un estado salvaje. Sobre el comportamiento corporal, se hace hincapié en la crispación y la exaltación creciente, participando ambos aspectos en la experiencia desapacible de la migración forzada. Como ejemplo de estos usos, en uno de los primeros tramos de la huída, los personajes del asesino y de la monja se asocian y logran llegar a un espacio urbano neutral. La relación entre ambos aparece marcada por la desconfianza y la ausencia de 
diálogo. Especialmente, el personaje femenino no emite palabras sino gemidos y sonidos incomprensibles que dificultan la comunicación. Como consecuencia, el asesino la persigue y la asedia, extrapolando las conductas de los victimarios y de las víctimas al interior del grupo de exiliados. Por otra parte, la inclusión del personaje con discapacidad mental, mediante movimientos inquietantes y torpes, el balbuceo, la profusión de onomatopeyas y el babeo constante, presenta algunos puntos de contacto con las propuestas del teatro de la crueldad, en tanto el cuerpo agobiado metaforiza una doble opresión social. La que desde tiempos remotos se ejerce sobre individuos que padecen la enfermedad, y la que en el presente histórico en que se realizó la película impartía el gobierno militar argentino en los ciudadanos ${ }^{12}$.

10 Como es posible comprobar, la condición del exiliado político y la puesta en relieve del estado de terror que lo singulariza se relacionan en este film con una serie de tópicos que recorren las experiencias cotidianas del expatriado, que vive el desarraigo y la puesta en suspenso de sus actividades y de su vida familiar y social. En estas circunstancias, de acuerdo con lo expuesto por Ana Amado para el caso de algunos films argentinos realizados en los años 80 en torno a estos temas, se pone en juego la doble dimensión del extrañamiento personal de la patria y las alusiones a una patria dividida (política y socialmente), la ausencia obligada frente a la necesidad de recuperar el territorio (Amado A., 2009) ${ }^{13}$. En estas disyuntivas encuentran un sentido los enfrentamientos que se suceden entre los personajes y la imperiosa necesidad de preservar la vida de la madre, portadora de una nueva vida.

\section{Hay unos tipos abajo. El exilio interior y la experiencia de la soledad}

11 Hay unos tipos abajo, estrenado en Buenos Aires el 26 de septiembre de 1985 a casi dos años de la restauración de la democracia, tematiza y elabora audiovisualmente la variante del exilio interior. Dada las particularidades del film, en comparación con las otras respuestas que encaminaron los ciudadanos frente a la dominación estatal, esta modalidad del exilio abarca el aislamiento voluntario de aquellas personas que difieren o se oponen a la ideología dominante y a sus prácticas sociales y políticas. Ante la imposibilidad de salir del país pero tomando conciencia de la necesidad de recluirse con la finalidad de preservar la integridad moral y física, esta fue una de las decisiones adoptadas por un segmento amplio de los realizadores, actores y agentes cinematográficos en Argentina y en los países latinoamericanos que atravesaron regímenes militares despóticos y violentos (Camargo R., 2007) ${ }^{14}$.

12 Ante la sospecha de la vigilancia, Hay unos tipos abajo emplaza la vida cotidiana de un joven periodista gráfico (Julio) al perímetro conformado por su vivienda familiar y los alrededores ${ }^{15}$. Coincide con el film de Alejandro Doria analizado en el apartado anterior en representar el estado de terror vigente en los años del proceso militar, construyendo dispositivos narrativos y espectaculares muy precisos que manifiestan las reacciones y los estados emocionales de los sujetos inmersos en situaciones de vigilancia y persecución. Se diferencia, en tanto, en concentrar el desarrollo narrativo (al menos una gran parte del relato, con excepción de la última secuencia) a un espacio dramático acotado, visibilizando esta elección espacial las conductas esgrimidas por los victimarios (quienes intimidan y acorralan al protagonista) tanto como las réplicas de la víctima (aislamiento, soledad). El relato sitúa la historia en el último fin de semana 
del mundial de fútbol jugado en Argentina en 1978. Abstraído del campeonato que captura la atención de todo el país, el reportero es alertado por una vecina y luego por su pareja sobre la presencia de unos hombres misteriosos que vigilan la cuadra de su vivienda y que podrían ser integrantes de los grupos de tareas que funcionaban en esos años de dictadura identificando y secuestrando personas ${ }^{16}$. Partiendo de esta instancia angustiosa, el film pone en práctica un diseño narrativo y de puesta en escena destinados a constreñir dramáticamente las situaciones y a crear una atmósfera de suma opresión. En sus aspectos generales, la formulación espacial recurre a la confrontación de dos ámbitos contrapuestos, arriba/abajo, representando metafóricamente el primero la intimidad del departamento familiar y el segundo el mundo exterior amenazante. La puesta en escena se caracteriza por no ser ilustrativa sino expresiva y simbólica. En los espacios exteriores al hogar familiar abundan las escenas nocturnas en las cuales los contrastes luminosos, los espacios vacíos y el sonido en off de los pasos de los transeúntes inciden en la construcción de la subjetividad del periodista. Se suman, asimismo, la proliferación de las sirenas de los automóviles policiales y la presencia de personas en actitudes sospechosas, generalmente ejerciendo la observación y la vigilancia a una distancia prudente de sus víctimas y sin interactuar de manera evidente. El interior del hogar ofrece protección parcialmente, dado que el clima de amenaza y hostigamiento se proyecta incluso en esos espacios de privacidad. Como ejemplos, en el departamento de Julio abundan las puestas de cámara en picado y hasta las perspectivas cenitales que registran al personaje desde un ángulo superior del ascensor (cuando llega desde la calle y se dispone a ingresar a su vivienda) o desde una de las puertas del departamento (en los momentos en que se encuentra en las diferentes dependencias de su domicilio). Y aquellas que retratan su reflejo en el espejo del baño, exhibiendo la condición de vigilancia que permanece aún en la intimidad del hogar. Por otra parte, los permanentes cortes de luz y de la línea telefónica a los que se ve sometido el periodista, cruzan datos de la realidad de la época con la profusión de un efectivo clima de desfamiliarización de las situaciones y extrañamiento de la realidad. Así, la interrupción de los llamados telefónicos que Julio recibe diariamente no se interpreta como producto de un desperfecto técnico, sino ligada a actitudes que tienden a amedrantar la integridad emocional y moral del protagonista.

13 A partir de estos pocos datos del contexto, el reportero se sume en un estado de temor y paranoia creciente que tiene como consecuencias concretas el abandono del trabajo, de su pareja y de todo vínculo social. La vigilancia provoca en Julio un estado interior que desestabiliza y fractura su identidad. Motiva estas circunstancias la dualidad que caracteriza al personaje. Julio se presenta como un ciudadano común que no es afiliado a ningún partido político ni ha intervenido en acciones públicas; sin embargo la duda y la culpa lo sumen en un estado de angustia irreversible (Julio recuerda una situación de secuestro en la que no intervino directamente; en un diálogo con su pareja dice conocer casos de personas que han desaparecido). De acuerdo con este estado de terror, el desarrollo narrativo y dramático se caracteriza por la concentración dramática, la introspección y el aislamiento. Rafael Filipelli, uno de los directores del film, sostuvo sobre este personaje: "El hombre vaga y divaga y la película trabaja con el dato subjetivo del miedo" (La Nación, 1985). Julio decide replegarse sobre sí mismo y se dedica al hallazgo de los datos y las certezas que permitan explicar los motivos de la vigilancia. Pone en suspenso sus actividades laborales y se abstrae del fervor que provoca el inminente juego final de la copa del mundo que enfrenta a Argentina y Holanda. Su acotado itinerario dramático incluye recorridos sin rumbos certeros, que lo 
llevan de su casa a algunos puntos concretos (un quiosco de diarios, un café, la casa de su novia) para devolverlo a su departamento. La desesperación y el temor van pautando el crescendo dramático, dado que el personaje no logra dilucidar el cometido de los perseguidores, en tanto debe asumir a su vez la falta de solidaridad de algunos seres queridos (una pareja de amigos lo aloja unas horas en su casa y luego le exige que se retire). En su periplo dramático, es evidente que Julio emprende un viaje introspectivo, destinado a examinar sus sentimientos y sus impulsos, a ejercer la reflexión sobre su estado presente. Sin embargo, el peso del contexto y la inestabilidad personal lo inducen a sentirse enredado en una situación a la que no le encuentra salida. En los momentos en que Julio se dispone a reflexionar, ya sea en un bar o en su departamento familiar, el film ofrece indicios sobre la alteración y la fragmentación de la subjetividad del protagonista. En esas escenas la interpretación del personaje aparece despojada de los movimientos corporales cotidianos e incluso de la palabra, exacerbándose la presencia de un físico estático y frágil (Saura J., 2007).

列 ausencia de respuestas y de soluciones posibles a la situación de dominación y control experimentada, Julio responde con el aislamiento absoluto. En estos tramos finales, la reclusión interior se transforma en ostracismo. Sin despedirse de su pareja, en el momento exacto en que Argentina gana el mundial de fútbol y los integrantes de la Junta Militar levantan el trofeo ${ }^{17}$, el periodista decide abandonar la ciudad sin un rumbo fijo. En las últimas imágenes lo vemos bajar de un tren, en una estación no identificable geográficamente, presumiblemente de la provincia de Buenos Aires. Sintomáticamente, quizás preso por el miedo, decide abandonar su máquina de escribir en el asiento del tren. Con esta actitud, pone en suspenso -temporariamente o de forma permanente, no lo sabremos- el curso de su vida, despojándose del objeto que lo representa y a través del cual expresa sus ideas.

\section{Consideraciones finales}

En su devenir histórico el cine argentino se pronunció de diferentes maneras respecto de los hechos sucedidos durante la última dictadura militar, coparticipando en esta tarea la ficción y el documental en sus diferentes disposiciones estéticas e ideológicas. Sobre estas modalidades cinematográficas los historiadores y críticos han depositado frecuentemente su atención en el período inmediatamente posterior a la caída del régimen, dilucidando la emergencia de ficciones de corte realista -las ficciones reparadoras mencionadas en la introducción de este artículo- y de una serie de documentales de montaje que enarbolaban, cada uno a su manera, los valores del republicanismo y de la pacificación social. En algunas oportunidades, estableciendo una periodización más amplia sobre el tema de la transición política de la dictadura a la democracia, se han advertido ciclos cinematográficos más extensos que incluso se extendieron al presente histórico de la Argentina. Exponente de estas reflexiones, Ana Amado organizó la producción cinematográfica de las tres últimas décadas de acuerdo con la incidencia de las estrategias públicas de la memoria del terrorismo de estado. Teniendo en cuenta la expresión simbólica de las demandas de justicia esgrimidas por la sociedad y las iniciativas procuradas por el Estado a tales efectos, contempló la sucesión de las siguientes etapas histórico-cinematográficas: a. coincidente con la recuperación de las instituciones democráticas en los años 80 , un primer ciclo defendió 
la narrativa de las "víctimas inocentes" impulsada por las ficciones realistas o reparadoras; b. en los años 90 , década en la que el proceso social de elaboración del pasado reciente movilizó acciones de signo diferente y estuvo plagado de tensiones y contramarchas, el campo del cine dio a conocer narrativas que recogieron la experiencia política de los militantes y el relato de sus hijos destacándose la inflexión hacia nuevas dimensiones que articulaban la autobiografía, el testimonio y la suspensión de los límites entre ficción y documental y, c. el nuevo siglo, que en sus primeros años estuvo atravesado por las consecuencias de las políticas neoliberales que culminaron en un agudo estallido político y social (la crisis del 2001 y los años subsiguientes), con sus principales expresiones audiovisuales en las series televisivas (Okupas, 2001; Tumberos, 2002) y en la ópera prima de Lucrecia Martel, La ciénaga, de 2001 (Amado A., 2009). Sobre estas problemáticas, Jésica Stites Mor ofreció una reflexión más audaz, al definir la "cultura de la transición" como la búsqueda de la justicia social que se sostiene en la revisión constante de las memorias colectivas traumáticas o interrumpidas. Expandiéndose en el tiempo, en opinión de la autora, la transición antecede los años del último régimen militar, delimitándose a lo largo de las décadas tres generaciones de cineastas que la expresan de forma acabada: la primera generación, activa a fines de los años 60 y proscripta por otro régimen militar (el encabezado por el general Juan Carlos Onganía ), se caracterizó por haber sido testigo de los movimientos revolucionarios que se extendieron en Argentina y América Latina en ese tramo de la historia; la segunda generación, contemporánea al retorno de la democracia en 1983, estuvo involucrada con las políticas de la memoria que surgieron y se desarrollaron en los años del alfonsinismo; la tercera, surgida durante la crisis política y económica que vivió el país en torno al año 2001, se distingue por ser radical en sus acciones y por elegir el documental político-militante como medio de expresión popular (Stites Mor J., 2011).

Como es posible advertir a través de estas menciones y referencias suficientemente inclusivas, las ficciones hermético-metafóricas analizadas en este artículo no poseen un lugar protagónico en el panorama de los films que históricamente se posicionaron ejerciendo la crítica y la resistencia al poder militar ${ }^{18}$. Entre los factores que explican esta ausencia, es clave señalar que la circulación de los films que integran la tendencia ha sido sumamente restringida en las últimas décadas, tanto en la televisión y las salas cinematográficas (comerciales y de arte), como en los espacios académicos. Coyuntura que no facilitó la revisión de las películas y el conocimiento de sus propuestas expresivas y semánticas. En segundo lugar, las particularidades de producción y exhibición que presentaron los films (algunos tuvieron financiamiento estatal, la mayoría estreno comercial, solo algunos enfrentaron la censura) interfirieron, a nuestro juicio, en la inclusión de la tendencia en el horizonte de los films que confrontaron el régimen militar, valorándose en líneas generales, para los años de la dictadura especialmente, las realizaciones de los directores y colectivos cinematográficos que funcionaban de manera marginal o clandestina. La complejidad textual que singulariza a la corriente, la opción por una estética que confronta los modelos realistas-naturalistas y la consecuente representación oblicua del contexto político-social de referencia, son otros componentes que pudieron haber intervenido en la falta de trascendencia pública de la corriente. En otros términos, como han expresado algunos teóricos contemporáneos sobre las operaciones metafóricas y alegóricas, la producción de conocimientos por estas vías puede resultar clarificadora y concluyente; sin embargo, es necesario que se decanten las interpretaciones o que 
transcurra el tiempo para que estas aparezcan o se reafirmen (Angenot M., 1982; Maillard C., 1992).

17 Sintetizando las novedades señaladas en los apartados que articulan este trabajo, sostenemos que el valor de la tendencia radica en conciliar la audacia en sus niveles estético e ideológico. En el plano expresivo los films retoman los postulados del cine moderno argentino, especialmente de las vertientes que tendían a la opacidad y a la innovación en los planos narrativos y de puesta en escena. Articulaba con estas decisiones la perdurabilidad de un proyecto cinematográfico surgido en los años sesenta y puesto en cuestión por las políticas culturales y cinematográficas impuestas por el régimen militar. La puesta en funcionamiento de las prácticas alegóricas y metafóricas como principios constructivos de los relatos es otro aspecto a destacar, dado que incide en la formulación de relatos e imágenes potentes que desafían la referencialidad directa a favor de la complejidad y la multiplicación de los sentidos. Por otra parte, como se ha procurado exponer a partir del estudio de Los miedos y Hay unos tipos abajo, las perspectivas semánticas que ofrecen los films de la corriente no incluyen concesiones a la opinión pública de la época ni a las formas ficcionales tradicionales, eliminando cualquier tipo de resolución positiva o tranquilizadora. En esta perspectiva se visualiza la intención crítica y reflexiva de la tendencia, la decisión de incluir en los debates, con igualdad de responsabilidad, a los diferentes segmentos sociales. Y la de oponerse a las modalidades probadas o pasatistas que dominaron el panorama cinematográfico en los años de la dictadura y la postdictadura.

Sobre los dos films analizados fue de interés reconocer en ellos algunas de las formas a partir de las cuales se representó el control y la dominación social ejercida por el Estado y sus consecuencias directas, que abarcaron no sólo el exilio en sus distintas variantes sino a su vez los estados visibles de alteración y fragmentación de las identidades. Metodológicamente, estos films permitieron explicar la operatividad de las alegorías y de las metáforas en los diferentes niveles de los relatos (con especial atención en el plano narrativo, el diseño de la puesta en escena y la constitución del sistema de personajes). De esta manera, fue factible asociar la configuración de relatos expandidos en su plano narrativo y de puesta en escena a la figura del exilio exterior y la de los relatos constreñidos a la del exilio interior. Estas situaciones, caracterizadas en estos dos casos mediante la sumatoria de espacios dramáticos y geográficos (Los miedos) y el juego de espacios opuestos (arriba/abajo, en Hay unos tipos abajo), son afines a las propuestas de los restantes films que componen la tendencia, estableciéndose un efecto de corpus que tiende a la homogeneidad sin caer en el estereotipo. ${ }^{19}$ La representación de las víctimas y de los victimarios es otro dato a tener en cuenta, ya que los films presentan múltiples resoluciones distintivas y versátiles. Los miedos y Hay unos tipos abajo depositan su foco de interés en las figuras de las víctimas, trabajando de forma fragmentaria e indirecta la representación de los victimarios (ya hemos visto que Los miedos aluden a un poder institucional representado por individuos que ofician capturando y asesinando personas; y que Hay unos tipos abajo reduce el desempeño dramático de los victimarios/grupos de tarea); en tanto, otros films de la corriente que nos ocupa trasladan la función de los victimarios/opresores a algún integrante de la familia (la abuela de La nona, la figura materna de Los enemigos), y que incluso, ejerciendo una mayor actitud crítica, se abala la hipótesis de la movilidad o el intercambio entre las figuras de la víctima y el victimario (hemos visto que al interior del grupo de migrantes, en Los miedos, se reproducen las prácticas de la coerción y la violencia). Finalmente, si se tiene en cuenta el panorama cinematográfico de las épocas 
estudiadas, con la particular aceptación de las tendencias realistas, es evidente que los films presentan una serie de novedades en lo que respecta a los estilos de actuación. Los miedos otorga singular potencia a la corporalidad y a los encuentros físicos y controversiales entre los personajes; de forma que: "La película brilla por sus elementos más experimentales y abstractos: las sesiones de llantos y alaridos, la brutalidad del paisaje, la fisicalidad de las actuaciones, el fin del mundo inscripto en los cuerpos de los actores" (Buenos Aires Rojo Sangre, 2013). En tanto, Hay unos tipos abajo se detiene en un personaje que se retrae sobre sí mismo al punto de desnaturalizar su relación con el mundo. En su conexión con los espectadores, estas formas de actuación exhiben de forma extrema los estados interiores de los sujetos dramáticos, estableciendo un comentario crítico, desesperado y muy poco moralizador sobre las situaciones y conflictos que estos atraviesan.

\section{BIBLIOGRAPHY}

Amado, Ana, La imagen justa. Cine argentino y política (1980-2007), Buenos Aires, Colihue, 2009.

Camargo, Raúl, « El exilio interior. A modo de introducción », Revista La Fuga, número 7, Santiago de Chile, 2009.

Aguilar, Gonzalo, « Sutiles pasados. El cine documental y memoria en la Argentina de la postdictadura », Revista Archivos de la Filmoteca, número 70, Valencia, 2012.

Angenot, Marc, La parole pamphlétaire. Typologie des discours modernes, París, Payot, 1982.

Avellaneda, Andrés, « Prólogo », en AA.VV., Ficción y política. La narrativa argentina durante el proceso militar, Buenos Aires, EUDEBA, 2014.

Fernández Bravo, Álvaro y Garramuño, Florencia, « Introducción », en A. Fernández Bravo, F. Garramuño y S. Sosnowsky (Eds.), Sujetos en tránsito (in)migración, exilio y diáspora en la cultura latinoamericana, Buenos Aires, Alianza, 2003.

Flechter, Angus, Alegoría. Teoría de un modo simbólico, Madrid, Akal, 2002.

García Canclini, Néstor, « Noticias recientes sobre hibridación », en H. Buarque de Holanda y B. Resende (Orgs.), Artelatina: cultura, globalização e identidades cosmopolitas, Río de Janeiro, Aeroplano/Museo de Arte Moderno, 2000.

Lusnich, Ana Laura, « Opacidad, metáfora, alegoría: nuevas estrategias discursivas y marcas de la ideología imperante en el cine ficcional del período 1976-1983 », en A. L. Lusnich y P. Piedras (Eds.), Una historia del cine político y social en Argentina. Formas, estilos y registros, Volumen II, Buenos Aires, Nueva Librería, 2011.

Lusnich, Ana Laura, « De la resistencia al duelo: las ficciones sobre las dictaduras realizadas en Argentina y Chile entre 1973 y 1990 », Studies in Spanish \& Latin American Cinemas, Volumen 12, Intellect, 2014.

Maillard, Chantal, La creación por la metáfora: introducción a la razón-poética, Barcelona, Anthropos, 1992. 
Masiello, Francine, «La Argentina durante el proceso: las múltiples resistencias de la cultura », en AA.VV., Ficción y política. La narrativa argentina durante el proceso militar, Buenos Aires: Alianza, 1987.

Noriega, Gustavo, « Estética de la desaparición », en J. Jaime (Ed.), Historias extraordinarias. Nuevo cine argentino. 1999-2008, Madrid, T/B Editores, 2009.

Pellettieri, Osvaldo, El sainete criollo: del autor al actor, Buenos Aires, Galerna, 2008.

Said, Edward, Reflexiones sobre el exilio. Ensayos literarios y culturales, Barcelona, Debate, 2003.

Stites Mor, Jessica, Transition Cinema. Political Filmmaking and the Argentine Left since 1968, Pittsburgh, University of Pittsburg Press, 2011..

Saura, Jorge (Comp.), Actores y actuación, vol. II. Antología de textos sobre la interpretación, Madrid, Fundamentos, 2007.

Visconti, Marcela, «Lo pensable de una época. Sobre La historia oficial de Luis Puenzo », Revista Aletheia, volumen 4, número 8, abril 2014.

La Nación, « Emilio Alfaro y Rafael Filipelli en busca del lenguaje fílmico no habitual », 18 de agosto de 1985.

Buenos Aires Rojo Sangre, " "Los miedos, el apocalipsis según Alejandro Doria », 6 de noviembre de 2013. Disponible en línea:

http://fanboycave.wordpress.com/2013/11/06/buenos-aires-rojo-sangre-los-miedos-elapocalipsis-segun-alejandro-doria/. Página consultada El 5 de abril de 2014.

\section{NOTES}

1. Los historiadores y analistas políticos han interpretado la postdictadura argentina acotada al gobierno de Raúl Alfonsín o contemplando la larga duración, extendiéndose hasta la actualidad. Justifican estas posiciones diferentes hechos irrefutables : el gobierno de Alfonsín se esforzó por restituir el poder a las instituciones republicanas; sin embargo, debido a que numerosas situaciones históricas -el juicio y la condena a los militares implicados en delitos de lesa humanidad- se resolvieron en las décadas subsiguientes, con fuertes tensiones y contramarchas, la opción por prolongarla hasta estos días tiene sus aciertos.

2. Al momento de asumir la presidencia, Raúl Alfonsín dispuso la creación de la Comisión Nacional de Desaparición de Personas (CONADEP), destinada a recibir pruebas y denuncias sobre hechos y delitos ocurridos en época de la dictadura y remitirlas a la justicia, averiguar el destino o paradero de las personas desaparecidas, ubicar a los niños desaparecidos y/o sustraídos a la tutela de sus padres, y emitir un informe final. Asimismo, ese informe funcionó como antesala a los juicios a los responsables de los delitos cometidos en esos años.

3. Más allá del accionar de la censura, la autocensura y la persecución a numerosos directores, actores y técnicos, tres realizadores fueron asesinados en los años de la dictadura : Pablo Szir, Enrique Juárez y Raymundo Gleyzer.

4. Entre otros ejemplos, Esta voz... entre muchas, filmada en México por Humberto Ríos en 1979, y Todo es ausencia, realizada por Rodolfo Kuhn en Europa en 1984, se dedican a denunciar los delitos y las desapariciones ocurridas en Argentina y a recoger los primeros testimonios de las Madres de Plaza de Mayo. Por su parte, Reflexiones de un salvaje, filmada por Gerardo Vallejo en España en 1978, reflexiona sobre el motivo del exiliado, esta vez relacionando la experiencia del director con la de sus antepasados que emigraron desde Europa a Argentina en tiempos de crisis económica. 
5. La historia oficial ha sido emblemática en los años de la recuperación democrática, ya que se la consideró portadora de ideas simplistas sobre el pasado reciente. Incluso se llegó a sostener que su historia -una mujer que descubría que la madre biológica de su hija adoptiva había sido una joven desaparecida por los militares- se articulaba a partir de la Teoría de los dos demonios vigente en la época, la cual alineaba con igualdad de responsabilidades el terrorismo insurgente y la violencia ejercida por el Estado.

6. Nos referimos a los artículos "Opacidad, metáfora, alegoría: nuevas estrategias discursivas y marcas de la ideología imperante en el cine ficcional del período 1976-1983 ", 2011, y «De la resistencia al duelo: las ficciones sobre las dictaduras realizadas en Argentina y Chile entre 1973 y 1990 », 2014.

7. En Argentina, el origen y el desarrollo de las operaciones metafóricas y alegóricas se sitúan en los años 50 y 60, con las realizaciones de Leopoldo Torre Nilsson, León Klimovsky y Carlos H. Christensen. En ese contexto, la hipertrofia de los recursos narrativos (los procesos de fragmentación, opacidad narrativa, multiplicidad del punto de vista, desajuste respecto de las normas genéricas) y espectaculares (la complicación espacial y temporal de los relatos, la obstrucción de los encuadres), fueron interpretados como síntomas de la llegada de la modernidad al país, constituyéndose una retórica inmanente al campo cinematográfico local.

8. Los miedos: Dirección: Alejandro Doria. Guión: Alejandro Doria y Juan Carlos Cernadas Lamadrid. Intérpretes : Tita Merello, Soledad Silveyra, Miguel Angel Solá, Sandra Mihanovich, Aníbal Morixe, Lito González, María Leal. Estreno : 1980, prohibida menores 18 años. Hay unos tipos abajo : Dirección : Rafael Filipelli y Emilio Alfaro. Guión : Antonio Dal Masetto, Rafael Filipelli y Emilio Alfaro. Intérpretes: Luis Brandoni, Luisina Brando, Soledad Silveyra, Marta Bianchi, Emilio Alfaro, Elsa Berenguer. Estreno : 1985, prohibida menores 13 años.

9. El film está inspirado en Diario del año de la peste, de Daniel Defoe, obra de la cual se retoma la perplejidad de los personajes ante la peste y la estructura episódica y de crónica que facilita recoger y reconstruir el peregrinar de los sujetos dramáticos.

10. En el contexto del gobierno militar, los grupos de tareas se encontraban conformados por miembros de las diversas Fuerzas Armadas y de los cuerpos de seguridad del Estado, cumpliendo las funciones del secuestro, la tortura y los eventuales asesinatos y desapariciones de los objetivos señalados por la dictadura (opositores políticos, guerrilleros, intelectuales, dirigentes gremiales, familiares y amigos de todos estos), además de la gestión de los distintos centros clandestinos de detención.

11. Estrategias narrativas y espectaculares que caracterizaron a los directores y grupos modernizadores en Argentina desde mediados de los años 50, desde los tempranos antecedentes a la Generación del Sesenta, el Grupo de los Cinco y Hugo Santiago, entre otros.

12. El teatro de la crueldad, en las variantes propuestas por Antonin Artaud, Peter Weiss y Harold Pinter, plantea que la obra dramática debe dejar una huella duradera en el espectador. Los recursos atañen a la puesta en escena y a la interpretación del actor particularmente, para ello se suelen modificar las disposiciones habituales del escenario y se encamina una actuación que reduce la palabra hablada a favor de la gestualidad y los movimientos.

13. En su libro, Ana Amado analiza varios films realizados en Argentina en los años 80 sobre la problemática del exilio : El exilio de Gardel (Fernando Solanas, 1986), Sentimientos; Mirta de Liniers a Estambul (Jorge Coscia y Guillermo Saura, 1989) y Las veredas de Saturno (Hugo Santiago, 1989).

14. Raúl Camargo describe el estado del medio cinematográfico en Chile en el curso de la dictadura militar que se extendió entre 1973 y 1990, siendo la mayoría de la medidas tomadas en esta área (clausura de las escuelas de cine, reducción de la producción y de los subsidios, censura, persecución) extensibles a lo vivido en los países de la región que estuvieron sometidos a procesos dictatoriales (Argentina, Brasil, Uruguay, entre otros). En este contexto, las respuestas de los directores, actores y técnicos disidentes se dividieron. Muchos de ellos partieron al exilio, 
otros optaron por la reclusión y la suspensión de las actividades, los pocos continuaron en actividad con un discurso crítico. Quienes pudieron hacerlo, al no contar con el financiamiento estatal, recurrieron a fondos propios o al ejercicio de la publicidad como medio de vida.

15. El film adapta el cuento homónimo de Antonio Dal Masetto. El autor coescribió el guión junto con Alfaro y Filipelli y en 1998 lo publicó en formato novela. La presencia activa de la muerte y la represión que se ejercía de manera silenciosa sobre el cuerpo social son dos matrices que conectan las obras.

16. Es evidente que Julio y su pareja conocen el accionar de estos grupos parapoliciales. En sus conversaciones, utilizan los vocablos "levantarlo", "intimidarlo" y "listas negras", haciendo referencia a las actividades ilegales que en los años de dictadura se ejecutaban por fuera del estado de derecho.

17. Este momento culmine del campeonato de fútbol se ve en un televisor que Julio posee en su departamento, siendo un claro indicio de época.

18. Mejor suerte tuvieron otros exponentes cercanos a la tendencia estudiada -la filmografía de Hugo Santiago, el Grupo de los Cinco activo en los primeros años de la década del 'y conformado por Alberto Fischerman, Ricardo Becher, Raúl de la Torre, Néstor Paternostro y Juan Bautista Stagnaro-, que captaron el interés de los críticos y los estudiosos en múltiples oportunidades.

19. Si se revisan los films de la corriente, los que giran en torno de los tópicos del asedio y la reclusión de los sujetos dramáticos ( $\mathrm{La}$ isla, La nona, Los pasajeros del jardín, Los enemigos) contraponen espacios abiertos y cerrados y algunas variantes topográficas asociadas (adentro/ afuera, arriba/abajo). Por su parte, los que tematizan y construyen audiovisualmente el escape y la huída como respuestas al estado de terror (El poder de las tinieblas, Crecer de golpe, El hombre del subsuelo, El agujero en la pared, amplifican las líneas espacio-temporales de manera considerable. En todos los casos, el desarrollo narrativo y la puesta en escena ponen en evidencia de forma expresiva y potente los estados de ánimo de los victimarios.

\section{ABSTRACTS}

During last Argentine militar dictatorship (1976-1983), and first period of the post-dictatorship (1983-1989), the hermetic-metaphoric fictions constituted an alternative cinematographic tendency that showed the main conflicts of that time in a reflexive and critical way. The construction of opaque tales that evading the realistic-mimetic representation and the primacy of the allegorical and metaphorical operations as constructive principles were two textual features that gave uniqueness to the trend. With the intention of knowing the permeability of this cinematographic line in respect of the political practices and the situations of terror imposed in the years of non-constitutional governments, the present work proposes to analyze the representation of the domination against individuals and the society, with emphasis in the emplacements and/or the displacements of dramatical subjects and the reference to situations of internal and external exile. The second objective of the paper includes the identification, in these historical situations associated to discipline and social extreme control, of subjectivities characterized by fracture and instability. The development of both aspects will be focused on two outstanding films of the trend: Los miedos ["Fears"] (Alejandro Doria, 1980) and Hay unos tipos abajo ["Some guys downstairs"] (Rafael Filippelli and Emilio Alfaro, 1985). 
Durante la última dictadura militar argentina (1976-1983) y en la primera fase de la postdictadura (1983-1989), las ficciones hermético-metafóricas constituyeron una tendencia cinematográfica alternativa que supo plasmar los conflictos principales de la época de forma reflexiva y crítica. La construcción de relatos opacos que evadían la representación realista-mimética y la preeminencia de las operaciones alegóricas y metafóricas como principios constructivos fueron dos características textuales que le dieron singularidad a la tendencia. Con la intención de conocer la permeabilidad de esta línea cinematográfica respecto de las prácticas políticas y las situaciones de terror impuestas en los años de gobierno de facto, el presente trabajo analiza la representación de la dominación ejercida por el Estado sobre los ciudadanos y el conjunto social, con énfasis en los emplazamientos y/o los desplazamientos de los sujetos dramáticos y la alusión a las situaciones del exilio interior y exterior. En segundo lugar, el artículo se propone identificar, en estas circunstancias históricas asociadas al control social extremo, subjetividades que se caracterizan por la fractura y la inestabilidad. El desarrollo de ambos aspectos estará centrado en dos films destacados de la corriente: Los miedos (Alejandro Doria, 1980) y Hay unos tipos abajo (Rafael Filipelli y Emilio Alfaro, 1985).

Pendant la dernière dictature militaire argentine (1976-1983), et ensuite, dans la première phase de la post-dictature (1983-1989), la fiction hermético-métaphorique s'est avérée une tendance cinématographique alternative qui a montré les principaux conflits de l'époque de manière réflexive et critique. Cette tendance se caractérise par le développement de récits chiffrés et éloignés de la représentation réaliste et mimétique, et qui donnent une importance toute particulière à des éléments allégoriques et métaphoriques. Ce travail se propose d'étudier la perméabilité de cette tendance

cinématographique par rapport aux pratiques politiques et aux situations répressives et traumatiques imposées par le gouvernement de facto. Pour ce faire, premièrement, nous analyserons la représentation de la domination exercée par l'État sur les individus et la société, en soulignant les positions et/ou les déplacements des sujets dramatiques et les références à l'exil intérieur et extérieur. Deuxièmement, l'article cherche à identifier de subjectivités fracturées et instables - dans le contexte historique caractérisé par un extrême contrôle social. Ces aspects seront analysés à partir de deux films importants de cette tendance: Los miedos (Alejandro Doria, 1980) et Hay unos tipos abajo (Rafael Filipelli et Emilio Alfaro, 1985).

\section{INDEX}

Mots-clés: Cinéma argentin, dictature, post-dictature, fiction, allégorie, métaphore, discipline sociale

Palabras claves: Cine argentino, dictadura, postdictadura, ficción, alegoría, metáfora, dominación social

Keywords: Argentine Cinema, dictatorship, post-dictatorship, fiction, allegory, metaphor, social domination

\section{AUTHOR}

\section{ANA LAURA LUSNICH}

Ana Laura Lusnich es doctora en Filosofía y Letras con mención en Artes, Facultad de Filosofía y Letras, Universidad de Buenos Aires. Investigadora independiente del Consejo Nacional de Investigaciones Científicas y Tecnológicas (CONICET) y profesora adjunta de la Carrera de Artes, 
Facultad de Filosofía y Letras, Universidad de Buenos Aires. Puán 470, Ciudad Autónoma de Buenos Aires, CP 1424. alusnich@gmail.com 